\title{
Societal Changes and New Conditions for the Management of Large Construction Projects
}

\author{
Henrik Szentes ${ }^{*}$ and Per Erik Eriksson
}

Luleå University of Technology, 97187 Luleå, Sweden

\begin{abstract}
The construction industry is often described as mature, conservative and resistant to change in research studies, governmental reports as well as in media. Both scholars and policy makers thereby find it critical to encourage innovation, development, and change within the construction industry. This study takes on a different perspective by investigating changes that have actually taken place. The aim is to increase the understanding of both backgrounds of changes which occurred, as well as how the changes have entailed new conditions for the management of large construction projects in Sweden. People working as clients' project manager, contractors' project manager or design manager were interviewed to obtain their perceived views on changes influencing the execution of large construction projects. Substantial changes have taken place creating new conditions for the management of large construction projects and a better understanding of these new conditions is important when planning for new projects. Changes within the field are often reactions to societal changes, and thus often implemented in an uncoordinated way creating sub-optimization and problems for the personnel. It seems as if the reputation of the construction industry being conservative has become an institution it-self amongst many professionals within the industry, potentially creating a self-fulfilling prophecy.
\end{abstract}

Keywords: Change, conditions, construction, institutional, management, project, societal.

\section{INTRODUCTION}

The construction industry has often been described as a mature industry that is non-innovative, conservative and resistant to adopt changes [1-4]. In several countries, such as the UK, Australia, South Africa, Hong Kong, and Sweden, governmental reports state that the construction industry does not adopt changes and innovations to a high enough degree, highlighting the role of the construction client as a "driver" of change and innovation [5-9]. These and similar reports are part of a "reform movement", requesting changes in organization and management of construction projects [10]. According to Fernie et al. [10], so far changes continue to fall short of the aspirations outlined by the reform movement. As opposed to many other scholars, Bresnen et al. [11] mean that a clear enthusiasm for change has been discernible within the construction industry during recent years. However, a lot of research has identified critical barriers to change and renewal, arguing that implementing change is difficult within the construction industry $[11,12]$. Although there is a vigorous debate on the need for change and potential reasons for lack of change, empirical studies investigating which changes have taken place on a broader scale in the construction industry, and why, are scarce. In order to contribute with more input to the debate of the need for change in the alleged conservative construction industry it is important to improve our understanding of the changes that do occur.

*Address correspondence to this author at the Luleå University of Technology, 97187 Luleå, Sweden; Tel/Fax: +46920491000;

Email: henrik.szentes@ltu.se
Studies in other industries have shown how changes in the surrounding society have resulted in internal changes related to the organization and management of businesses $[13,14]$. The main argument is that companies are affected by societal changes and trends that occur within their external environment. These external changes are forcing or driving companies to implement new ways of organizing and/or managing their businesses in order to adapt to the changed conditions. New institutional theory provides a good framework for describing and explaining such changes occurring in the society in an increasing pace, and how these entail changes in different contexts and in specific organizational fields $[10,15]$. The term 'institutional' refers to normative and cognitive rules that organizations believe they need to adopt to reach legitimacy and stability [16]. Institutions themselves change, often due to inherent contradictions within the institution [17]. Sometimes a prerequisite for a change in organizational behavior is de-institutionalization, the weakening and diminishing of prevailing institutions [18]. However, institutions seem to have an ability to repair and conceal the contradictions that lead to institutional change or de-institutionalization [19]. Since the construction industry is often described as a mature industry, institutional theories may provide important insights regarding changes in this empirical context. One example from the Swedish construction industry is provided by Anna Kadefors [2], who concludes that construction projects should not only be studied from a project management perspective, but instead complemented by studying the institutionally imposed conditions at the macro level.

Considering the large volume of ongoing and planned large construction projects in Sweden, many of them tax 
funded, it is from a societal perspective important to better understand if and how the conditions for how to organize and manage such projects have changed over the years. Large construction projects are very much dependent on many different internal stakeholders as well as a variety of stakeholders in the surrounding society that directly or indirectly impose and constraints on the project [20]. Accordingly, how to organize and manage such projects is dependent on the conditions formed by internal and external stakeholders. Furthermore, changes and innovations are more likely to take place in larger construction projects because of their potentially larger budget for innovation related efforts as well as their longer duration [21].

In order to shed light on the topic of changed conditions for the management of large construction projects, this research investigates changes that have actually taken place. The purpose is to investigate how the conditions for the execution of large construction projects in Sweden have changed. The empirical material consists of collected stories about changes affecting the execution of large construction projects and the external sources of those changes, as perceived by people managing large construction projects.

The method section describes how the empirical material was collected and analyzed, followed by a result section comprising categorized stories about changes occurred. The subsequent section presents analyses of the reasons and backgrounds for changes described in the stories, as well as how the conditions for managing large construction projects have changed. The concluding discussion elaborates on insights related to institutional theory as well as on implications for the field by the changed conditions as such.

\section{METHOD}

This paper is based on qualitative research in which an inductive approach was used for exploring changed conditions over time for the management of large construction projects. The unit of analysis follows the definition of the term organizational field; "organizations that, in the aggregate, constitute a recognized area of institutional life; key suppliers, resource and product consumers, regulatory agencies, and other organizations that produce similar services or products" [22, p. 148]. In this paper we accordingly define our field and unit of analysis as; the arena in which all different stakeholders to large construction projects in Sweden meet and interact. This is a broad definition, but the idea is to avoid limitations in the analyses in line with what is stated by Dacin, Goodstein and Scott [18].

\section{Sample}

The primary data source was interviews with people who, at the time of the interviews, were working in different large construction projects. In this study, a large construction project was defined as having a contract sum above 50 million Euros, and comprising production of infrastructure, industry facilities, public buildings or offices. The 23 interviewees were working as design managers or as project managers for either the client or the contractor (see Table 1). This purposive sampling [23] was made to obtain views of changes that influence the execution of large construction projects, as perceived by the people managing such projects.
To minimize the influence on the interviewees, it was decided not to prescribe any specific time frame when asking the interviewees to describe changes that have occurred. In practice, the time frame was instead set by the age and prior experience of the interviewees in the sample. The average years of experience in the industry amongst the interviewees were 19 years, ranging from 3 years to 45 years providing a broad spectrum of project managers active in the field.

\section{Collection of Empirical Material}

All interviews were conducted in the project offices or similar, using a semi-structured approach with open-ended questions. The objective was to collect the interviewee's spontaneous thoughts of changes occurred that they perceive have an influence on the execution of their projects, and to let the interviewees elaborate on plausible reasons and origins. According to Mats Alvesson [24] the interviewee can be guided to certain answers due to interpretations and expectations on what the researcher is looking for, both prior to the interview as well as in the interview situation. In an attempt to mitigate that risk only brief information regarding the aim and purpose of the study was given prior to the study, and each interview started with wide and general questions while more specific questions about the interviewee's background concluded each interview. To increase trust and openness, information about how the gathered information would be treated anonymously in the research process was presented, though this does not at all guarantee that the interviewees will not adapt their stories due to political agendas or due to fear of being exposed with deviating opinions [24].

All interviews were recorded digitally, and after weighing pros and cons of transcripts [24, 25] it was decided not to fully transcribe all recordings. Instead detailed field-notes with time notations were used for initial analysis, making it easy to go back to the recordings to listen for further details and clarifications and make transcriptions of specific parts.

\section{Analysis}

Qualitative content analysis was used to structure the changes, inspired by grounded theory in the sense that categories of changes emerged during the analysis instead of being based upon previous research [26]. The categories represent different changes influencing the execution of large construction projects, though effects, reasons and sources are described in each category. The criterion for choosing the final list of categories was that overlaps between categories should be minimized and that each category should be based on several independent interview statements.

The change categories where then further examined by analysing the different types of underlying reasons and sources of changes occurred, and by analysing how the conditions for managing large construction projects have changed.

\section{EMPIRICAL RESULTS - CHANGE CATEGORIES}

The interviews resulted in stories of how the execution of construction projects has changed over the years, as perceived by people working in project management positions. 
Table 1. Information about the 23 Interviewees

\begin{tabular}{|c|c|c|c|c|c|c|}
\hline$\#$ & Party & Gender, Age & Education & Years in the industry & $\begin{array}{l}\text { Previously employed by other } \\
\text { types of actors }\end{array}$ & $\begin{array}{l}\text { Worked } \\
\text { abroad }\end{array}$ \\
\hline 1 & Client & Female, 33 & M.Sc. Civil Eng. & 8 & Contractor & Yes \\
\hline 2 & Contractor & Male, 54 & M.Sc. \& Econ. & 24 & No & Yes \\
\hline 3 & Design & Male, 41 & M.Sc. Civil Eng. & 17 & No & Yes \\
\hline 5 & Contractor & Male, 39 & B.Sc. Constr. & 17 & No & Yes \\
\hline 6 & Design & Male, 39 & M.Sc. Civil Eng. & 15 & No & Yes \\
\hline 7 & Client & Male, 29 & M.Sc. Civil Eng. & 6 & Structural Eng. & No \\
\hline 8 & Contractor & Male, 37 & M.Sc. Civil Eng. & 13 & Structural Eng. & No \\
\hline 11 & Design & Male, 45 & High Sch. Constr. & 25 & Contractor & No \\
\hline 12 & Client & Female, 30 & M.Sc. Mechanics & 3 & No & No \\
\hline 13 & Client & Male, 48 & M.Sc. Civil Eng. & 24 & Structural Eng., Contractor & Yes \\
\hline 14 & Contractor & Male, 44 & M.Sc. Civil Eng. & 17 & No & Yes \\
\hline 15 & Process Contractor & Male, 48 & B.Sc. Undefined & N/A & N/A & Yes \\
\hline 16 & Process Contractor & Female, 29 & M.Sc. Energy & N/A & N/A & No \\
\hline 17 & Client & Male, 66 & High School & 45 & No & No \\
\hline 23 & Contractor & Male, 35 & M.Sc. Civil Eng. & 10 & Carpenter & No \\
\hline
\end{tabular}

Several interviewees were surprised when they were asked to describe and elaborate on changes that they had perceived over the years. The initial spontaneous response was often a bit sarcastic and humorous explaining that the construction industry is conservative by nature and that change is scarce.

"I almost replied: have there been any changes within the construction sector?"..."The construction sector is very conservative, almost a bit too conservative" (Contractor)

"It is a sector that is rather difficult to change, everyone says." (Client)

"We are so immensely bound to old ways of doing things; this is how we do, and how we shall always do." ... "This sector really is traditional" (Design Manager)

However, after some reflection most interviewees were able to identify several changes within the industry as well as in the surrounding society that entail changes for the execution of large construction projects.

\section{Organizational Structure}

\section{Matrix Organizations and Specialization}

Some interviewees argue that the use of different setups of matrix organization has increased, entailing that many specialists are today organized in corporate staff functions serving multiple projects with competence simultaneously. This seems to be the case for both clients, contractors and consultants, though stronger on the client side. The interviewees expressed that this development has increased the variety of roles and the number of people involved in large construction projects, as well as the number of companies involved. Moreover, the control of resources decrease, and tensions are created between objectives in the different projects as well as towards objectives set in the line organization creating sub optimization. New specialist roles in projects are for example BIM-experts, PR-experts, legal advisers, purchasers and financial controllers. The reason for this development is partly an increased technical and administrative complexity increasing the competence requirements in dif- 
ferent areas thus requiring specialization. One client representative expressed that strong staff functions and the use of matrix organizations was an organizational trend causing more trouble than benefits:

"Some resources are organized in centralized support functions. I believe that that is really stupid, and that the matrix organization is the worst possible organizational structure."...'It creates a situation in which experts are not always aware of the project objectives, entailing that those experts run their own show at a very different level of ambition, higher or lower. Quite often they are not cost consciousness enough, not from the project's point of view."..."They often strive towards technical excellence instead of technical-economical optimization." (Client)

\section{Smaller Permanent Client Organizations}

Another change related to organizational structure is that many permanent client organizations have decreased in size, hence they have become much more dependent on consultants from a great variety of companies, entailing that continuity and experience exchange between projects is affected negatively. However, it is easier for the client's project manager to appoint the most appropriate resources for each project instead of being forced to pick resources from internal staff. The main driver for this development seems to be to save costs by being able to continuously adapt the organizational size to the actual project portfolio. Three interviewees representing the client side in this study were consultants.

"One thing that is obvious, is that client organizations have become much slimmer" ..."The need for external competence has increased, in areas such as project management, risk management and technical competence. Earlier, this kind of competence was more often found in-house" (Client).

\section{Organizational Units in Other Countries}

The international competition in the field has increased somewhat, though most international competitors are still from northern Europe. Indirectly, this development also entails that the execution of projects require interaction with units abroad. Swedish contractors and consultants have also benefitted from the increased internationalisation. It has become more common that contractors purchase materials directly from abroad using an internal organizational unit specialized on international purchasing, often with offices abroad. Another strategy, which is similar but not as common, is to outsource design to low cost countries.

\section{Business Relations}

\section{Contractual Aspects}

The use of Design-Build contracts has increased, and according to some interviewees working for the Swedish Transport Administration (STA) their plan is to actively continue this trend as regards infrastructure projects to further engage the contractors in the design of roads, bridges, harbours and similar.

"As we in the future further shift from Design-Bid-Build to Design-Build contracts we will need to organize ourselves in a different way, with more design competence available also in the production phase." (Client)
This is a bit contradictory to the occurrence of construction management solutions in the area of large building contracts where it has become a bit more common to split the construction work into smaller contracts. According to one interviewee on the contractor side, this make planning and resource allocation problematic for the involved contractors since they lack overview and are often engaged much later in the process.

Over the years, the Swedish standard contracts for construction work (AB, ABT, etc.) have gone through a series of changes and adaptations to better suit the purpose, e.g. in the distribution of responsibility and risks between the parties. Despite the globalization of the entire society, international contracts are rarely used.

\section{Partnering and Collaboration}

The most frequently mentioned change was partnering and similar collaborative approaches. Most interviewees were enthusiastic, but some argued that partnering is more of a political trend and a fashionable word rather than a real change in how the parties collaborate:

"Partnering approaches requires more people and more time spent."..."We are caught in the trap, right now partnering is the preferred approach" (Client)

"From time to time, different themes are diffused throughout the sector; quality, green buildings, health \& safety, and right now partnering" (Contractor)

"In reality, this is not a partnering project, we do not have that kind of dialogue, and I believe that there is no formal partnering facilitator." (Design Manager)

There are many variants of partnering used, stretching from an ambition of open communication between the client and the main contractor, to full partnering with joint economy and incentives covering most parties involved. This variety of partnering setups generates confusion for the people working in projects. Partnering requires a larger organization to deal with all the necessary communication and the continuous joint decision-making. Another effect mentioned was that partnering approaches make it possible to wait longer for certain decisions and that the tendency is that decisions are more often changed, creating stress and tensions. It has become more common that people shift role/party within the industry, creating a better mutual understanding and dialogue between the parties, making the introduction of partnering easier. The empirical material suggests that the introduction of partnering is an attempt to overcome problems with poor communication and fighting over change orders and similar, and as regards tax funded projects a way to meet complaints from the public on how money is spent, though the full explanation is most likely more complex and full of nuances.

\section{Additional or Intensified Scope and Requirements}

\section{Environmental Focus}

Environmental requirements on buildings and specified low energy consumption have become more common in contracts, often specified by demanding specific environmental certificates such as: LEED, BREEAM, and Green Building. These contract requirements cause additional pressure on the design and build processes including increased amount of 
documentation, new stakeholders to manage, and a need for new competence and engagement on-site.

"The strong focus on the environment is the greatest change."..."Low energy consumption too, but today it is even more important to e.g. avoid health-endangering materials" (Design Manager)

"The amount of administration has increased enormously the recent 15 years. "... "Foremost due to new routines covering areas such as environment and health \& safety" (Contractor)

\section{Interaction with the Public}

The level of interaction with the public has increased, mainly because the public in general have become more informed, educated, engaged and demanding. Indirectly, urbanization also causes this trend since construction sites more often than before are situated in urban areas. An increased environmental interest in society together with a lowered tolerance regarding disturbances as noise amongst people living or working near construction sites create new expectations and requirements on projects. The number of stakeholders increases accordingly, and the demands from the public are not as defined as project goals, or the requirements set by authorities. Indirect effects are increased demands on documentation and planning, and intensified focus on non-disturbing production methods. To cope with the situation, more people are needed in the organization, with expert knowledge in communication, but also in specific technical areas. However, these effects seem not to be taken into account to a high enough extent in the bid phase, causing a strain on project management not to increase the cost for personnel, thus increasing the pressure on the existing organization.

"An increasing awareness and knowledge in the surrounding society and by people in general has made us rethink and change focus"..."We as contractors meet many more specialists today, not at least specialists working for the client" (Contractor)

"The society has changed in a way that everything is more intense today, everything goes faster."... "The large projects are supposed to be built without being visible or making any disturbances for the public." (Contractor)

\section{Investment Strategies}

Buildings are more often than before produced after the end customer is contracted instead of speculative production to stock. Even though the scope is not increasing, an intensified pace is required in the construction phase due to shortened production time available following the fact that the end customer most often wants the building rapidly once the investment decision is made.

"One increasingly important aspect in all construction projects that impacts on how to organize and manage site activities is time pressure. Previously, more houses were built on speculation, whereas today the client most often wants to have contracts with tenants in place before the project is fully initiated." (Client)

"Today contractors aspire much more to get the client's customer satisfied."..."Some change orders are too easily accepted, entailing time pressure and stress." (Contractor)

\section{Politics, Legislation and Authorities}

Construction activities have become more dependent on political decisions, which are often hard to predict in terms of time and content. Planning has become more difficult, and since the finalization date is often fixed the time available for production decreases, causing a need for higher pace in the production phase.

"Politics has to a much larger extent become crucial for this kind of projects during the recent 20 years. Sometimes local politicians have a great impact, and in other cases projects are dependent on regulations e.g. regarding taxes." (Contractor)

The Public Procurement Act (PPA) that was originally introduced in Sweden in 1992 and then went through a major revision in 2008 also imposes great changes to the field, e.g. by regulating the conditions for communication between the parties during the tender phase.

In the 1990's the Swedish construction law went through a major revision, changing the distribution of responsibility for quality control. The role "Construction inspector" representing the client was eliminated and replaced with an administrative routine called "self-control", giving the contractors both the responsibility and authority to control their own work, using documentation and checklists. However, one client argued the control efforts by the clients have started to increase again.

"The client requires more information in written format; oral agreements are not as valid as before. "..."The production journal kept on-site is almost worthless today in juridical terms, the client refuses to make any economic decisions based upon the information in the journal, but still urges that the information in it must be correct. " (Contractor)

Although most of the interviewees talked positively about the focus on health and safety, they also emphasized some complicating effects: more people on-site are required including specific H\&S-coordinators, more focus on precautionary measures is expected, and more documentation is required to fulfil requirements from Swedish Working Environment Authority. Similar effects were mentioned to be the result of the increased requirements of interaction with, and dependency on decisions by other authorities such as County Boards and the Environmental Court. The entry to the European Union has also imposed new regulations, norms and legislation.

\section{Technology, Methods and Tools}

\section{Industrialized Construction}

Focus on productivity and effective construction processes has increased over the years. The use of prefabricated solutions and industrialized approaches now seems to be a trend, and large contractors have introduced a set of standardized technical solutions for certain construction details based upon experience.

"Prefabricated solutions, that production is made offsite, has in my opinion increased, and will continue to increase, for example with prefabricated installation rooms and similar, not only structural frames." (Design Manager) 


\section{Information Technology}

The use of information technology has become more common, and the variety of IT-solutions and tools have grown: Computer aided design work including advanced structural engineering tools, Building Information Models (BIM), project document databases, E-mail, and knowledge seeking as well as spreading information using intranets and the internet. Most interviewees were positive and saw good opportunities in these developments.

"The use of project document databases makes my job much easier." (Design Manager)

However, some interviewees argued that this development requires new specialist competence on-site and a strict and consistent use of the appointed IT-tools and systems or there is a risk of delusive imaginary accuracy.

"We are today working much more with 3D-design and with collision control using Navis Works"..."One indirect problem with this is that the increased level of details required in the model makes people believe that things that are not present in the model should not exist in reality at all. The model looks exact and definite even when the structure presented is not at all detailed designed. This urges us to be far more thorough."

Moreover, BIM requires an adapted flow of decisions in the design phase; hence a new design process with less flexibility. Some concern was raised on whether the variety of IT-tools and systems support the production or if they only cause more administration. One driver behind this change is technological development, but also that people who have grown up with computers and internet are now working in the field.

\section{Logistics}

Logistics have increased in importance: The increasing urbanization entail smaller areas for storage on construction sites and increased dependency on the traffic situation. Cost consciousness has also forced contractors to optimize logistics, and the focus on health \& safety has increased the requirements on safe transports, unloading, and handling of materials. Accordingly, the sophistication and the competence in the area of logistics have increased.

\section{New Materials and Technical Solutions}

Over the years several new materials and technical solutions have been introduced to the construction industry. The reasons for this development are a mix of business related mechanisms, but also indirect as a response to e.g. legislation and increasing environmental care No matter the reason, the effect is that the technical complexity and the variety of competencies required in the construction process have increased.

\section{HR-Related}

\section{Internationalization of the Workforce}

It has become quite common that contractors deploy work forces from abroad, most often in different subcontractor setups. These developments have led to more complicated communication due to language barriers and cultural aspects, shift work, and demands on documentation in multiple languages increase the workload and is an additional source of errors.

"The internationalization creates specific problems, with cultural differences regarding the content and process of design activities as well as production". (Client)

However, it was also emphasized that internationalization is a catalyst for change and development and the introduction of new methods and approaches. Of the 23 interviewees in this study 11 had worked abroad.

\section{Age, Experience, Gender, and Education}

Many people in the industry have retired during the recent 10 years, leaving a gap of experience in many areas and a lowered average age of people working as project managers and in similar supervising roles (the average age of the 23 interviewees in this study was 41 years). The newcomers are often better in open communication and dialogue, but sometimes have difficulties in decision-making.

"One striking change is "shift of generations" and a new age structure. It seems as if we in the younger generation are less interested in doing as one has always done and are instead more interested in establishing good cooperation and production." (Client)

As an effect of the financial crisis in the early nineties in Sweden, many people left the construction industry resulting in a lack of people born in the sixties which makes the current intensive pace of retirements more problematic. Furthermore, many interviewees expressed that the lack of experienced supervisors is aggravated due to that supervisors with university degrees often look for new challenges after 1-2 years. As a result, it has become more common to recruit supervisors and site managers with craftsmen backgrounds. This development is starting to erode the boundaries between supervisors and craftsmen, but traditions and unions were mentioned as strong resistors of this potential unification of work forces. A majority of people working in project management positions have a Master of Science degree in Civil Engineering, though the variety of university educations present in construction projects is increasing. The amount of women have increased slightly, though there were e.g. only three female interviewees in this study. Most women active in the construction industry are not involved in the on-site production; rather they hold positions related to centralized support functions.

\section{Gender Equality and Family Responsibilities}

Expectations from society regarding shared responsibility for family related matters and gender equality have increased dramatically in Sweden. Considering the demographic changes mentioned above, this creates tensions, a need for more flexible working hours, and alternative ways of coping with daily tasks. More than half of the interviewees expressed rather strong examples of tension between work and private life - and most of those had young children. Amongst the interviewees that expressed that there was no tension between work and private life few had young children. Some interviewees even explicitly mentioned grownup children as a main reason why their situation was satisfactory. Two of the largest issues expressed were that the inter- 
viewees are expected to be reachable at all times, and that the daily commuting is time consuming.

"I am currently on parental leave two days a week."..."My wife is also working in the construction industry, she is a contractor."..."We have discussed how our private life suffers from this, but it is an active choice to enable work with stuff that is interesting." (Client)

"We represent the modern family, I get the children from kindergarten now and then and sometimes I drop them off. "..." However, my wife is currently working $60 \%$ of fulltime so she takes a greater responsibility for family related tasks."..." I do bring work home; I think of it and elaborate on different issues and tasks; it takes energy, and it is easy to lose focus on kids and family."(Contractor)

"There is not much time left for private life, which is tough, I quite often feel tired."..."We have a subcontractor that works 7-22 in weekdays and 7-15 on Saturdays"...'I have a wife and one small child." (Contractor)

\section{TRANSITIONS FROM SOCIETAL CHANGES TO NEW CONDITIONS FOR THE FIELD}

To achieve an overview of the transitions from changes in the surrounding society, through the defined change categories, and further to changed conditions for managing large construction projects, further analyses were conducted. First, societal changes that were commonly mentioned by the interviewees were identified and then summarized into seven different blocks. Second, an analysis of changed conditions for managing large construction projects that are common for different change categories as described by the interviewees were conducted. Third, a mapping of the transitions was conducted, presented in Table $\mathbf{2}$ and Table $\mathbf{3}$. It is important to understand that there might be non-societal drivers behind the changes, e.g. business driven. However, this research focuses on societal change forces mentioned in the empirical material. Moreover, the study gives no information as regards the level of connection between the different changes.

\section{CONCLUDING DISCUSSION}

This study sets out to investigate if and how changes in the surrounding society have changed the conditions for how large construction projects are executed, in order to increase our understanding of how to manage current and future projects. Although many interviewees spontaneously said that the construction industry is conservative, all of them presented and discussed a fair amount of changes after thinking a while. Accordingly, the stories presented in the results section clearly show that substantial changes have taken place in the field of Swedish large construction projects over the years. The conditions for the organization and management of large construction projects have changed accordingly, which is summarized in Table 3. These findings contrast previous research that argues that there are a lack of changes in the Swedish construction industry [9]. However, the finding that many changes within the field have evolved at least partly as a reaction to external changes rather than as a proactive encouragement of innovation, indicate conservative thinking and behaviour. Some conditions have changed in a way that creates opportunities whereas some seem to make management more complicated, though the empirical material does not provide information enough to make a proper evaluation of the effects. The important conclusion is that the new conditions need to be taken into account when executing current and future large construction projects. The new conditions will affect decisions of organizational structure and delegation of authority, as well as allocation of resources, and appointment of key personnel including the project manager.

The specialization and use of matrix organizations lead to that different functions within the parties react to different external changes, and sometimes in different ways to the same external change. This entails a lack of overview and control of the responses, and to potential sub-optimization where positive effects of one response gets eroded or even eliminated by other responses. One specific perspective that seems often to be forgotten is the effect that these uncoordinated responses mean to the people working in the field. In the spirit of development, new routines, processes, and ways of working are introduced without taking enough into account the summarized effect on the workforce in terms of increased workload and complexity, lack of motivation and unsatisfied personnel.

Another possible effect of new ideas being implemented as responses to external changes is that new solutions or ways of working are being implemented without proper analyses of the business case. Similarly, the establishments of trends in the field may also entail broad implementation of certain solutions and ways of working without proper analyses of the benefits in the specific project. This kind of concern was raised by some interviewees as regards partnering and certain information technology. In their study from 2002, Greenwood, Suddaby and Hinings [27] conclude that professional associations has an important though complex role to play in terms of legitimizing changes in highly institutionalized fields. In their view, the often suggested conservative role is on one hand true in some stages of change, but in other stages the role shifts to the opposite. Nevertheless, professional associations have a great impact on what ideas that becomes trends in the field, and how these trends are presented.

According to Dacin, Goodstein and Scott [18], many changes require a de-institutionalization to take place to make ground for the new ideas. It seems as if the swift changes in demography of the people working in the construction industry and the increased diversity of educational backgrounds have contributed strongly to the deinstitutionalization of many prevailing ways of working, enabling alternatives to be developed. For example, the increased use of information technology, industrialized approaches and improved logistics, international procurement of both material and services, and the use of more collaborative contractual approaches. However, there are also examples where institutions have prevailed even when legislation has changed. One example of this is the use of constructionsite journals that on one hand no longer has any contractual meaning or power, but on the other hand seems to still be in use and sometimes requested by clients. This phenomenon is very similar to what Harry Sminia [19] refers to as "institutional continuity". 


\section{Table 2. Transitions Between Societal Changes and Change Categories}

\begin{tabular}{|c|c|}
\hline Societal Change & Change Categories \\
\hline \multirow{3}{*}{$\begin{array}{l}\text { Globalization } \\
\text { All aspects of the world becoming more integrated: International suppliers, } \\
\text { global politics, harmonization of legislation and regulations, and integration } \\
\text { of labour markets. }\end{array}$} & Organizational units in other countries \\
\hline & Politics, legislation and authorities \\
\hline & Internationalization of the workforce \\
\hline \multirow{2}{*}{$\begin{array}{l}\text { Urbanization } \\
\text { The increasing proportion of the population living in urban areas results in } \\
\text { more challenging logistics in cramped construction sites and interaction } \\
\text { with neighbours. }\end{array}$} & Interaction with the public \\
\hline & Logistics \\
\hline \multirow{5}{*}{$\begin{array}{l}\text { Demographical processes } \\
\text { Changes of different attributes of the population entail direct effects in } \\
\text { terms of new attributes of the workforce. Indirectly, new forms of } \\
\text { collaboration and new tools are enabled, but a need for more interaction } \\
\text { with the public is also an indirect effect. }\end{array}$} & Partnering and collaboration \\
\hline & Interaction with the public \\
\hline & Information Technology \\
\hline & Internationalization of the workforce \\
\hline & Age, experience, gender and education \\
\hline \multirow{7}{*}{$\begin{array}{l}\text { Values and Attitudes } \\
\text { Different societal processes that entail changes of values and attitudes } \\
\text { amongst the population, sometimes enable alternative and new approaches } \\
\text { and solutions, but often cause increased workload as well as complexity in } \\
\text { terms of working hours and similar }\end{array}$} & Partnering and collaboration \\
\hline & Environmental focus \\
\hline & Interaction with the public \\
\hline & Politics, legislation and authorities \\
\hline & New materials and technical solutions \\
\hline & Age, experience, gender and education \\
\hline & Gender equality and family related responsibilities \\
\hline \multirow{3}{*}{$\begin{array}{l}\text { Democratic processes } \\
\text { Processes that lead to increasing transparency, and more power to the pub- } \\
\text { lic. Some effects are direct, whereas some effects are indirect through legis- } \\
\text { lation and regulations. }\end{array}$} & Interaction with the public \\
\hline & Politics, legislation and authorities \\
\hline & Gender equality and family related responsibilities \\
\hline \multirow{5}{*}{$\begin{array}{l}\text { Technological developments } \\
\text { All aspects of technological development: products, solutions, and methods } \\
\text { for design and production. Indirectly these developments require a greater } \\
\text { diversity of competencies, often enabled by the use of matrix organizations. }\end{array}$} & Matrix organizations and Specialization \\
\hline & Industrialized production \\
\hline & Information Technology \\
\hline & Logistics \\
\hline & New materials and technical solutions \\
\hline \multirow{9}{*}{$\begin{array}{l}\text { Productivity and revenue } \\
\text { All aspects of increased focus in the society on productivity and revenue. } \\
\text { This focus is part of the explanation to many of the change categories, } \\
\text { though most of them also originate from other societal changes. }\end{array}$} & Matrix organizations and Specialization \\
\hline & Smaller permanent client organizations \\
\hline & Organizational units in other countries \\
\hline & Contractual aspects \\
\hline & Partnering and collaboration \\
\hline & Investment strategies \\
\hline & Industrialized production \\
\hline & New materials and technical solutions \\
\hline & Internationalization of the workforce \\
\hline
\end{tabular}




\section{Table 3. Transitions Between Change Categories and Changed Conditions}

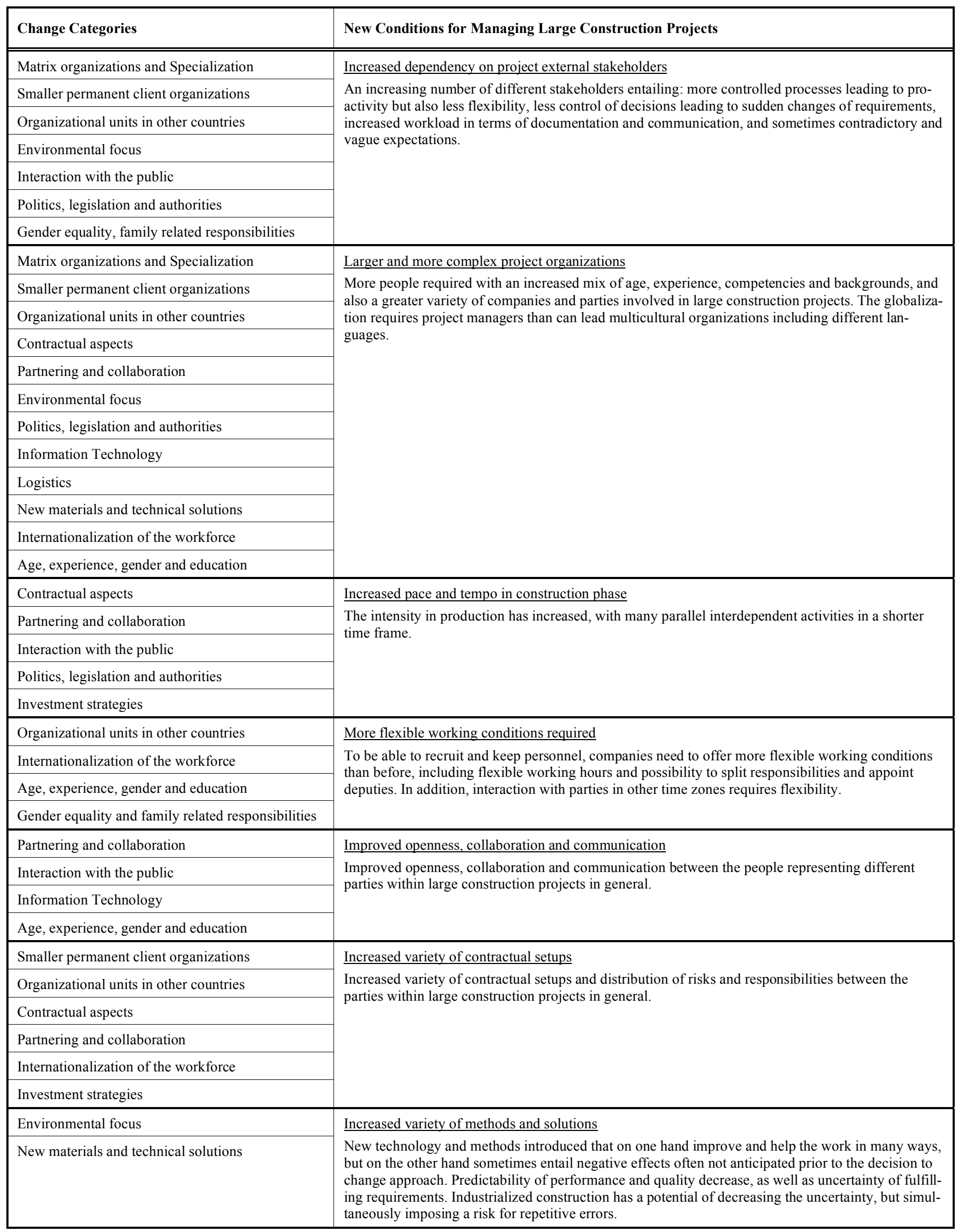


The reputation of the construction industry being conservative seems to have become institutionalized as such. There are several statements by the interviewees showing that many professionals in the industry believe that the industry is conservative by nature. It might be that this kind of statements is of habitual nature and that the continuation of this institution is unintended [19]. Nevertheless, following the principles of institutional theory, this imposes a risk of a self-fulfilling prophecy blocking innovation and developments to take place and making the construction industry less attractive to people prone to development and change.

According to the empirical material the increased pace and tempo in the field can be traced back to societal changes. However, there are also some concerns raised over the workload generated by new technology and new methods used in the field. These concerns can be interpreted as conservative thinking, but it is important not to take that assumption for granted. Instead one may consider the possibility that some developments in areas such as logistics, production methods, and information technology generate increased pace and tempo rather than being the solution to externally imposed requirements on increased tempo.

It seems clear that a strong trend is industrialized approaches including prefabrication and standardization of certain components. The aim is to gain effectiveness and productivity, but also to improve control of quality. These standardization processes do decrease the variety of solutions and should bring down uncertainty, but ironically this development simultaneously imposes a risk of repetitive errors similar to what is traditionally associated with e.g. the car industry. One related issue is how insurances will cover repetitive errors in the construction industry?

It is a bit of a paradox that the organization required to execute a typical large construction projects as of today is larger and more complex containing many more specialists than before, and that at the same time clients have shrunk their permanent organizations. This has opened up a great market for consultant companies, but also some concerns regarding continuity and knowledge sharing within client organizations. Furthermore, one must consider how this situation affects the implementation of partnering approaches where the client representatives are in reality contracted by the client in a separate commercial agreement: Do those people feel they can be open enough, and do they have enough mandate from the client to really make the swift decisions necessary for progress in a partnering project?

There is potentially a tension between globalization and the ambition and societal change to share the responsibility for family matters. Having organizational units in other time zones require availability before and after normal working hours, and contractors and subcontractors from abroad often prefer to work long days in longer periods and then stay home for a week or so. Even though the latter is often regulated in contracts, both situations make it even harder for supervisors and project managers to leave work in time and then stay off-line.

A limitation with this qualitative research is that it does not provide explicit information on the magnitude of each change, nor does it provide an answer to the aggregative nature of each change though some effects mentioned in the change stories are obvious to be positive or negative. To achieve such validating results a more quantitative approach would be encouraged in future research. More research is also required to further investigate how the changed conditions for executing large construction projects presented in this study affect project management as regards e.g. governance structure, and project manager's personality, education, experience, and managerial style. Furthermore, considering the successive development of gender equality in different parts of the world and the fact that gender equality is rather strong in Sweden [28], it would be interesting to further investigate how the development of gender equality and shared responsibility for family matters has influenced the field and the industry as a whole.

\section{CONFLICT OF INTEREST}

The author(s) confirm that this article content has no conflicts of interest.

\section{ACKNOWLEDGEMENT}

For financial support, The Development Fund of the Swedish Construction Industry, SBUF, are gratefully acknowledged.

\section{REFERENCES}

[1] E. Ekstedt, R. Lundin, and H. Wirdenius, "Conceptions and renewal in Swedish construction companies", European Management Journal, vol. 10, no. 2, pp. 202-209, 1992.

[2] A. Kadefors, "Institutions in building projects: implications for flexibility and change", Scandinavian Journal of Management, vol. 11 , no. 4 , pp. $395-408,1995$.

[3] M. Riley, and D. Clare-Brown, "Comparison of cultures in construction and manufacturing industries", Journal of Management in Engineering, vol. 17, no. 3, pp. 149-158, 2001.

[4] J. Rooke, D. Seymour, and R. Fellows, "Planning for claims: an ethnography of industry culture", Construction Management and Economics, vol. 22, no. 6, pp. 655-662, 2010.

[5] M. Latham, Constructing the Team. London: HMSO, London 1994.

[6] Construction Task Force, Rethinking Construction. Construction Task Force Report for Department of the Environment, Transport and the Regions, HMSO, London 1998.

[7] Royal Commission, Final Report of the Royal Commission into the Building and Construction Industry. Royal Commission into the Building and Construction Industry, Melbourne 2003.

[8] Construction Industry Review Committee, Construct for Excellence: Report of the Construction Industry Review Committee. HKSAR Government, Hong Kong 2001

[9] SOU, Byggkommisionen: Skärpning gubbar! Om konkurrensen, kvaliteten, kostnaderna och kompetensen i byggsektorn, [Construction Commission: Tighten up guys! About competition, quality, costs and competence in the construction sector]SOU 2002: 115. Department of Environment and Society, Stockholm 2002.

[10] S. Fernie, R. Leiringer, and T. Thorp, "Change in construction: A critical perspective”, Building Research \& Information, vol. 34, no. 2, pp. 91-103, 2006.

[11] M. Bresnen, A. Goussevskaia, and J. Swan, "Implementing change in construction project organizations: exploring the interplay between structure and agency", Building Research \& Information, vol. 33, no. 6, pp. 547-560, 2005.

[12] A. Vennström, and P.E. Eriksson, "Client perceived barriers to change of the construction process", Construction Innovation, vol. 10 , no. 2 , pp. $126-137,2010$ 
[13] M. Tushman, and C. O'Reilly, "Ambidextrous organizations: managing evolutionary and revolutionary change", California Management Review, vol. 38, no. 4, pp. 8-30, 1996.

[14] S. Raisch, "Balanced structures: designing organizations for profitable growth", Long Range Planning, vol. 41, no. 5, pp. 483-508, 2008.

[15] G.F. Davies, and C. Marquis, "Prospects for organization theory in the early twenty-first century: institutional fields and mechanisms", Organization Science, vol. 16, no. 4, pp. 332-343, 2005.

[16] J.W. Meyer, and N. Rowan, "Institutionalized organizations: formal structure as myth and ceremony", American Journal of Sociology, vol. 83, no. 2, pp. 340-363, 1977.

[17] M. Seo, and D. Creed, "Institutional contradictions, praxis, and institutional change: A dialectical perspective", The Academy of Management Review, vol. 27, no. 2, pp. 222-247, 2002.

[18] T.M. Dacin, J. Goodstein, and R.W. Scott, "Institutional theory and institutional change: introduction to the special research forum", Academy of Management Journal, vol. 45, no. 1, pp. 43-56, 2002.

[19] H. Sminia, "Institutional continuity and the dutch construction industry fiddle", Organization Studies, vol. 32, pp. 15-59, 2011.

[20] J. Söderlund, "Pluralism in project management: navigating the crossroads of specialization and fragmentation", International Journal of Management Reviews, vol. 13, pp. 153-176, 2011.
[21] P.E. Eriksson, S. Olander, H. Szentes, and K. Widén, "Managing short-term efficiency and long-term development through industrialized construction", Construction Management and Economics, 2013. In Press.

[22] P.J. DiMaggio, and W.W. Powell, "The iron cage revisited: institutional isomorphism and collective rationality in organizational fields", American Sociological Review, vol. 48, pp. 147-160, 1983.

[23] D. Silverman, Interpreting Qualitative Data, $3^{\text {rd }}$ edition. SAGE Publications Ltd 2006.

[24] M. Alvesson, Intervjuer - genomförande, tolkning och reflexivitet. [Interviews - execution, interpretation and reflexivity] Publisher Liber 2011.

[25] S. Kvale, Den kvalitativa forskningsintervjun The qualitative research interview. Publisher Studentlitteratur 1997.

[26] J. Hartman, Vetenskapligt tänkande. [Scientific thinking] Studentlitteratur 2004

[27] R. Greenwood, R. Suddaby, and C.R. Hinings, "Theorizing change: the role of professional associations in the transformation of institutionalized fields", Academy of Management Journal, vol. 45, no.1, pp. 58-80, 2002.

[28] R. Hausmann, L.D. Tyson, and S. Zahidi, The Global Gender Gap Report 2012, World Economic Forum, 2012.

(C) Szentes and Eriksson; Licensee Bentham Open.

This is an open access article licensed under the terms of the Creative Commons Attribution Non-Commercial License (http://creativecommons.org/licenses/by-nc/3.0/) which permits unrestricted, non-commercial use, distribution and reproduction in any medium, provided the work is properly cited. 